\section{A NOVEL LAPAROSCOPIC PULSE OXIMETER DEVICE: AN EASY, EFFICIENT AND COST-EFFECTIVE WAY OF DETECTING ARTERIAL STRUCTURES}

Theodosios Theodosopoulos, MD, PhD, Anneza Ioannis Yiallourou, MD and Emmanouil Stamatakis, MD, PhD
Theodosopoulos T, Yiallourou AI, Stamatakis E. A novel laparoscopic pulse oximeter device: an easy, efficient and cost-effective way of detecting arterial structures.

J Clin Monit Comput 2011; 25:145

Letter to the Editor-in-chief of JOCM,

To whom it may concern,

Dear Sirs,

In response to the article by S.M. Lopez et al. entitled "On Laparoscopic Photopleysmography and Pulse Oximetry" published in your journal in the (2010) 24:219-220 issue, we would like to point out that our idea for laparoscopic pulse (palmic) oximetry was submitted to and patented in December 2008 by the Industrial Property Organization of Greece, and it received National Patent Number 1006661 and International CL8:A61B 17/28.

We are at your disposal for any further verification/ queries on this matter,

Yours faithfully,

Theodosopoulos et al.
From the Aretaieion Hopsital, Athens, Greece.

Received 28 November 2010. Accepted for publication 4 February 2011.

Address correspondence to A. I. Yiallourou, MD, Aretaieion Hopsital, Athens, Greece.

E-mail: annyiallo@yahoo.gr 